\title{
Validation of metacognitive academic writing strategies and the predictive effects on academic writing performance in a foreign language context
}

\author{
Mark Feng Teng ${ }^{1}$ (D) Chenghai Qin ${ }^{2}$ C Chuang Wang ${ }^{3}$
}

Received: 13 January 2021 / Accepted: 24 August 2021 / Published online: 14 September 2021

(C) The Author(s), under exclusive licence to Springer Science+Business Media, LLC, part of Springer Nature 2021

\begin{abstract}
This empirical study serves two purposes. The first purpose is to validate a newly developed instrument, the Metacognitive Academic Writing Strategies Questionnaire (MAWSQ), which represents the multifaceted structure of metacognition in an English as a Foreign Language (EFL) academic writing setting. The second purpose is to delineate the predictive effects of different metacognitive strategies on EFL academic writing performance. Data were collected from 664 students at a university in mainland China. Confirmatory factor analyses (CFA) provided evidence for the fit for two hypothesized models, i.e., an eight-factor correlated model and a one-factor second-order model. Model comparisons documented that the one-factor second-order model was a better model, through which metacognition functions as a higher order construct that can account for the correlations of the eight metacognitive strategies, pertaining to declarative knowledge, procedural knowledge, conditional knowledge, planning, monitoring, evaluating, information management, and debugging strategies. Results also provided evidence for the significant predicting effects of the eight strategies on EFL academic writing performance. The empirical evidence supports the transfer of metacognition theory from educational psychology to interpreting EFL academic writing.
\end{abstract}

Keywords Metacognition · Metacognitive knowledge $\cdot$ Metacognitive regulation · Academic writing $\cdot$ Language learning strategies

Chenghai Qin

scottcn@hainanu.edu.cn

Mark Feng Teng

markteng@um.edu.mo

Chuang Wang

wangc@um.edu.mo

1 Faculty of Education, University of Macau, Macau, China

2 School of Foreign Languages, Hainan University, Haikou, China

3 Faculty of Education, University of Macau, Macau, China 


\section{Introduction}

Students learning English as a foreign language (EFL) struggle with academic writing. The challenges in enhancing EFL academic writing are multi-dimensional. One reason may be the lack of awareness and use of writing strategies (Ruan, 2014). EFL academic writing is acknowledged as a challenging component for university students (Teng, 2019a). The challenges in EFL academic writing are exacerbated because of the limited English language input afforded to student writers. English academic writing competence has thus become a common concern in the EFL contexts. As student writers were described as having different repertoires of strategies in learning to write (Raimes, 1987), the level of "self-initiated thoughts, feelings, and actions that writers [used] to attain various literary goals" may have been different (Zimmerman \& Risemberg, 1997, p.76). Hence, the instruction of academic writing needs more attention.

In Chinese universities, regardless of discipline, English is a compulsory course. Students often need to take a compulsory English course that is typically limited to four hours per week. The amount of instruction time focused on English writing is limited, and students receive little practice in writing. In addition, the education system in China is examoriented. Facing pressures related to the national standardized test, such as the College English Test (CET), English teachers often focus on the instruction of grammar, accuracies, and paragraph structures (Woodrow, 2011). Indeed, students may find themselves confused with word choice, grammatical use, generation of ideas, and organization of structures (Wang \& Wen, 2002). Due to time constraints, low motivation, and low English proficiency, writing still remains a challenging dimension in Chinese EFL teaching and learning (Reynolds \& Teng, 2021). Teachers seem to lack incentive to cultivate students' motivation and regulation for writing (Hall \& Goetz, 2013). In recent years, Chinese universities are paying more attention to non-English majors' academic writing performance to compete for global rankings. Students may feel more pressure because academic writing is not just related to the use of the English language but also involves gaining international recognition in a specific discipline.

In EFL contexts, teaching academic writing is product-oriented. For example, the curricula, syllabuses, and assessment related to academic writing are prescribed by administrative committees (Zhao, 2010). Related to this, students were passive and thus failed to "develop strong beliefs in the relevance and importance of writing" (Bruning \& Horn, 2000, p.26). This phenomenon may explain why student writers were not interested in having much involvement in the academic writing process, leading to the deprivation of self-regulation in academic writing. To become a proficient writer, they may exert effort to acquire knowledge of vocabulary and grammar, rather than to build an awareness of achieving high levels of self-regulation (Graham \& Harris, 2000). Lacking "self-awareness, self-motivation, and behavioral skills" to implement knowledge for academic writing, student writers may not be able to "transform their mental abilities into academic skills" (Zimmerman, 2002, p.65-66). Self-regulatory capacity thus becomes an important factor that may predict students' academic writing performance.

Hence, there is a need for considering metacognition, self-regulation, and writing, for which learners need to rely on metacognitive strategies in self-regulating their writing processes. There is also a call for a need to innovate the teaching of EFL academic writing. For example, we may adopt process-oriented writing instruction, an emerging trend in EFL writing (Zeng, 2005), to the instruction of academic writing. We now recognize academic writing as a tremendously complicated cognitive act that requires planning, text generation, 
and revision (Flower et al., 1994). The instruction of academic writing may involve guiding students to reflect on their writing process and their use of metacognitive strategies. In realizing such a goal, student writers may face constraints in taking control of academic writing. The development of academic writing is in the hands of those who understand, plan, set goals for writing tasks and react to, and reflect on what has been written (Sasaki et al., 2018). In this respect, we see a potential in assessing EFL learners' use of metacognitive academic writing strategies and the predictive effects of metacognitive writing strategies on academic writing. The purpose of the present study is thus twofold: (a) to validate a questionnaire about metacognitive strategies on academic writing; and (b) to explore the extent to which strategies predict EFL students' academic writing performance. Findings can shed light on the understanding of metacognitive strategies on EFL academic writing. Teachers can thus gain insight on how to foster instruction of targeted metacognitive writing strategies for students. A final contribution is the potential for researchers to transfer educational psychology theory, e.g., self-regulation and metacognition, to EFL academic writing pedagogy.

\section{Literature review}

\section{Metacognition}

Metacognition is multidimensional and domain-general in nature. Earliest stage of metacognition is developed from the theory of mind approach (Flavell, 1979). For example, metacognition is the practical application of theory of mind to cognitive tasks. Knowledge from theory of mind provides the conceptual underpinnings essential to the development of metacognition (Lockl \& Schneider, 2006). Metacognition fills "a unique niche in the selfregulatory phylum," through providing "domain general knowledge and regulatory skills that enable individuals to control cognition in multiple domains" (Schraw, 2001, p. 7). Metacognition is thus a critical awareness of one's own thinking processes and the executive processes in attempting to regulate their cognitive processes as a thinker and learner (Flavell, 1979).

Flavell (1979) delineated metacognition as serving two basic functions, namely the monitoring function and control of cognition. For example, metacognition, "through the monitoring function, is informed by cognition and, through the control function, informs cognition" (Efklides, 2008, p.278). Efklides (2006) included metacognitive knowledge and metacognitive experiences as the monitoring function and metacognitive skills as the control of cognition. Flavell (1985) suggested person, task, and strategy knowledge comprised metacognitive knowledge. Based on Wenden's (1998) assertions, person knowledge refers to a learner's knowledge about his or her cognitive processes and any possible factors, such as age, language aptitude, and motivation, that may impact the learning performance. Task knowledge involves the knowledge essential to understanding the purpose, nature, and demands of various tasks. Strategy knowledge includes the knowledge of the strategies that can help achieve the goals and effectiveness of learning tasks. Paris et al. (1984) argued that metacognitive knowledge should include declarative, procedural, and conditional knowledge. Declarative knowledge refers to a learner's skills, intellectual resources, and processing abilities. Procedural knowledge covers the knowledge required to figure out how to implement a task through deploying strategies. Conditional knowledge includes learners' knowledge of 
discerning when and why to use specific strategies for a relevant task. Flavell (1985) also named metacognitive knowledge and metacognitive regulation as knowledge of metacognition and regulation of metacognition.

In addition to metacognitive knowledge, other researchers also called for attention to metacognitive experiences and metacognitive skills (e.g., Efklides, 2008). Metacognitive experiences refer to what individuals are aware of and what they feel when they must process information related to a coming task (Efklides, 2006). For example, metacognitive experiences included feelings and judgments of knowing, effort expenditure, solution correctness, task difficulties, task familiarity, and self confidence. Metacognitive experiences form a platform for an individual to build awareness of a task that needs to be performed. Metacognitive feelings are both affective and cognitive in nature and can be considered within the broader mechanism of self-regulation behavior.

Metacognitive skills were described as metacognitive strategies or metacognitive regulation, including planning, conflict resolution, error detection, and inhibitory control (Shimamura, 2000). Metacognitive skills comprise orientation strategies, planning strategies, cognitive processing strategies, monitoring strategies, and evaluation strategies (Veenman \& Elshout, 1999). Brown (1987) defined metacognitive regulation as how learners identify distracting internal and external stimuli to sustain effort over time for executive functions. According to Schraw (1998), metacognitive regulation entails three skills: planning, monitoring, and evaluating. Planning refers to the ability to seek appropriate selection of strategies and adequate allocation of resources for relevant tasks. Monitoring is the ability to observe and check on the task performance. Evaluating taps into the ability to appraise the regulatory processes and learning products. Schraw and Dennison (1994) added two metacognitive strategies, i.e., debugging strategies and information management strategies. Debugging strategies refer to the ability to correct comprehension and performance errors. Information management strategies cover skills in processing, organizing, elaborating, and summarizing information efficiently. We developed the following figure to illustrate metacognition (Fig. 1).

The above figure provides insight into the conceptualization of metacognition. First, metacognition consists of two aspects: monitoring function and control of cognition. The feature of the metacognitive system is a kind of dominance relation. Thie metacognition system was for the flow of information. The information flow gives rise to a distinction between "control" and "monitoring" (Nelson, 1996). The three major stages, i.e., acquisition, retention, and retrieval, are between the control and monitoring levels. Metacognition is thus a conscious process, through which an individual is consciously aware of the monitoring and control processes. Second, the monitoring function includes metacognitive knowledge and metacognitive experiences while the control function involves initiation of metacognitive skills or strategies. Third, metacognitive experiences and skills direct learners' ability to regulate their cognitive processes, for which we described as metacognitive regulation (e.g., planning, monitoring, evaluating). Reflection is a fundamental part of the plan-monitor-evaluate process. Finally, metacognition is an individual phenomenon that reflects one's knowledge, experiences, and skills in metacognition. Metacognitive knowledge, metacognitive experiences, and metacognitive skills are interrelated. For example, metacognitive knowledge may influence learners' metacognitive experiences, their feelings and judgments of writing efficacy, which in turn, influence their use of metacognitive strategies in self-regulating their writing process. 


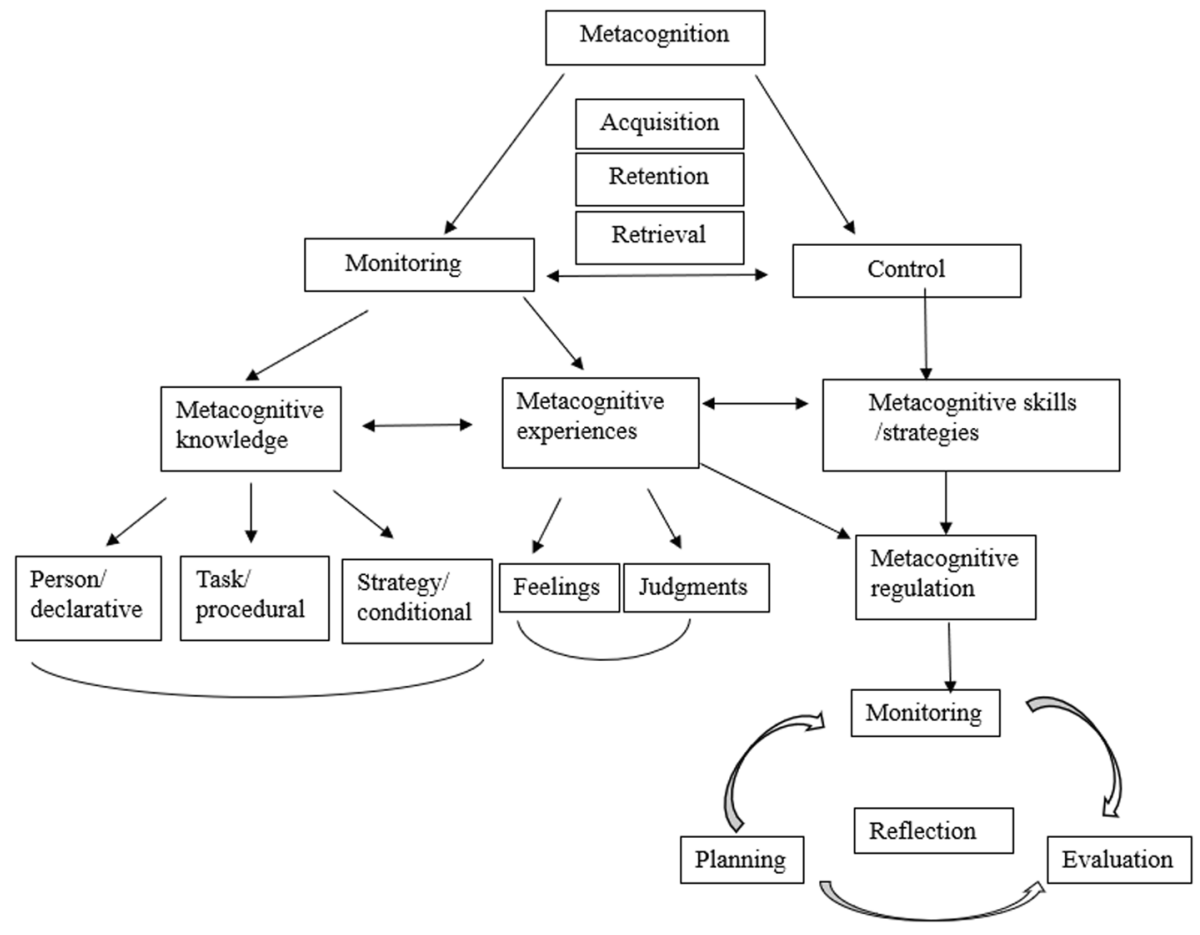

Fig. 1 Multi-faceted elements of metacognition

\section{Metacognition, self-regulation, and writing}

Metacognition reflects one's ability in self-regulated learning (SRL). SRL incorporates three classes of regulation: covert (personal), behavioral, and environmental (Zimmerman \& Risemberg, 1997). Covert self-regulation refers to the "adaptive use of cognitive or affective strategies" to reduce anxiety in learning. Behavioral self-regulation pertains to "the adaptive use of a motoric performance strategy." Environmental self-regulation involves "the adaptive use of a context-related strategy" (p.77). When a learner can exert strategic control over the three classes of regulation, he or she can be described as a learner of metacognitive awareness (Zimmerman, 1989). As Zimmerman and Schunk (2001) argued, SRL includes parameters-personal processes, environmental events, and behavioral attributes - that enable a learner to identify a topic, set goals to become familiar with the topic, adopt strategies to examine the topic, and evaluate and modify the relevant strategies for a deeper understanding of the subject matter. Indeed, self-regulated learners can often draw upon different metacognitive strategies to discern how to control their beliefs, behaviors, and external environments in the learning process (Zimmerman, 2013), thus allowing them to regulate "learning strategies as well as internal and external learning resources (e.g., motivation, learning environment)" (Ziegler et al., 2011, p.76). Hence, SRL reflects learners' ability to "plan, monitor, and regulate" their learning through taking control of their "thoughts, feelings, and actions" (da Silva Marini \& Boruchovitch, 2014, p.323). SRL strategies were acknowledged as building upon cognition, metacognition, social behavior, and motivational regulation (Oxford, 2013; Zimmerman, 2011). Learners 
deployed different metacognitive strategies to "guide them toward being effective learners without reliance on teacher-imposed structure and control" (Andrade \& Evans, 2012, p.21). Oxford (2013) categorized strategies into four groups: metacognitive strategies that guide the planning, monitoring and evaluating process; affective strategies that manage emotions and motivation; cognitive strategies that analyze and synthesize information; and social-interactive strategies that emphasize collaboration. Those various strategies form the basis for the strategic self-regulation model. Exploring how metacognitive writing strategies influence students' EFL academic writing performance becomes necessary. The present study thus focuses on metacognitive strategies, a central dimension of SRL strategies.

Metacognitive strategies influence writing. In an early model on thinking and speech (Vygotsky, 1987), transition from thought to word was described as a very complex process and required deliberate analytical actions. Although Vygotsky's model did not focus on writing, based on this model, we may assume that writers need to create a web of meaning connecting prior and present experiences and knowledge to maximally compact inner speech to be understood by the readers. Translating thoughts into words requires learners to repeatedly revise their output to a standard of quality. Such demands are assumed to require varied metacognitive strategies to enhance their effectiveness in writing.

Later models of the writing process acknowledged the strategies involved in planning, monitoring, and reviewing the writing process. For example, based on an early writing model proposed by Flower and Hayes (1980), writing was conceptualized into three components, i.e., task environment, long-term memory, and the writing process. The process of writing was described to include planning the writing (e.g., generating information, setting goals, and organizing information), translating ideas into text, and reviewing the draft (e.g., evaluating and revising text). In a later cognitive model of knowledge telling/knowledge transforming (e.g., Bereiter \& Scardamalia, 1987), two strategies, i.e., rhetorical and selfregulatory strategies, were suggested as mental subroutines that can enhance writing. The two models provided insight into the cognitive interactive aspects of writing. The cognitive act of writing spawned investigation of differences in writing between expert and novice student writers. Such differences included strategies in planning, translating and reviewing, and monitoring. Indeed, compared to experts who could employ cognitive methods to garner and sustain affective experiences and motivation, novices were less able to set writing goals, monitor their output based on their writing goals, and revise text at an organizational level (Teng \& Huang, 2019). Hence, writing activities are usually "self-planned, self-initiated, and self-sustained," for which learners need "self-initiated thoughts, feelings, and actions" to attain various literary goals, including "improving their writing skills as well as enhancing the quality of the text" (Zimmerman \& Risemberg, 1997, p.76). The assumption is that if skilled writers can employ metacognitive strategies to control the triadic influences in writing, novice writers can also benefit from instruction on relevant metacognitive strategies.

Based on the above models, metacognition may pervade the writing process. Learners need to rely on metacognitive strategies to plan, monitor, and regulate their writing process. Indeed, the meaning-making process is a conscious process (Flower, 1989). Such a process may reflect the interconnection between metacognition, self-regulation, and writing. For example, construction of meaning is a part of metacognitive development. Such an argument may reflect Hyland's (2003) writing process paradigm, in which writing is "essentially learnt, not taught" (p. 18). We also see the value of possibly exploring metacognitive strategies for helping learners express meaning in writing.

Some empirical studies support the importance of metacognition and self-regulation in writing. For example, instruction about metacognitive writing strategies (i.e., planning, 
feedback handling, monitoring, and evaluating) facilitated students' reflection, monitoring, and evaluation of the metacognitive processes (Teng, 2016). Similarly, Bui and Kong (2019) incorporated metacognitive instruction for peer review in L2 writing and claimed that their training of metacognitive strategies strengthened learners' belief and perceptions and increased their level of engagement and collaboration for L2 writing. As argued by Sun and Wang (2020), the effectiveness of metacognitive writing strategies may be related to learners' strengthened self-efficacy belief. Ma and Teng (2021) described different learners' metacognitive knowledge and the relationship with writing development. Their findings showed that learners of different language proficiency demonstrated different development trajectories of metacognitive knowledge and writing development.

In a recent study (Teng, 2020), instruction on metacognitive strategies included two groups: group feedback guidance and self-explanation guidance. Results collected from 120 Chinese students revealed the positive effects of group metacognitive support on writing. Metacognitive awareness can help learners manage themselves and prevail over writing-related setbacks. As argued by Hacker et al. (2009), metacognitive awareness can help writers maintain a "privileged position," in which they can "generate the thoughts they wish to write, and monitor and control that generation of thoughts... [while they] translate those thoughts into writing, and they monitor and control that translation" (p. 161). In a longitudinal study that explored metacognitive awareness, writing, and self-regulation (Negretti, 2012), data were collected from journals written by 18 students. Results showed that metacognitive awareness mediates learners' perceptions of writing tasks and self-regulation. For example, metacognitive awareness facilitates learners' ability to adapt their strategic choices to the specific writing requirements. Self-regulatory experiences lead to an enhanced awareness of conditional and personal strategies. In particular, monitoring and evaluation are associated with learners' writing task perception and their awareness of effectiveness in metacognitive writing strategies. Teng's (2019b) study focused on instruction of metacognitive strategies for self-regulated learning. Results showed the effectiveness of fostering metacognitive strategies for young learners' writing, in line with Harris and Graham's (2009) research. In addition, promoting automaticity of metacognitive strategies resulted in "spare attentional resources that contributed to high-level processes of generating ideas and organizing them into sentences" (Teng, 2019b, p.292). As supported in a longitudinal study (Teng \& Zhang, 2021), learners' L2 writing development was dependent on their initial level of metacognitive knowledge.

The above studies established the basis for understanding the relationship between metacognition, self-regulation, and writing. Challenges in developing learners' metacognitive strategies may be a reason for learners' lack of proficiency in writing. It is essential to foster learners' awareness of metacognitive strategies. As metacognitive strategies are multidimensional, exploring the different strategies used to gain insights into learners' strengths and weaknesses and how such awareness can predict learners' writing performance, appears to be essential.

\section{Language learning strategies based on SRL and metacognition}

Learning strategies are "cognitive plans oriented toward successful task performance" (Schunk \& Zimmerman, 2012, p.62), or the tools for learners to achieve active, self-directed involvement in developing learning capacity (Wenden \& Rubin, 1987). Strategies include activities or techniques for selecting and organizing information, rehearsing learned materials, allocating new materials for information in memory, and creating and maintaining a positive learning 
climate (e.g., enhancing self-efficacy) (Weinstein \& Mayer, 1986). Strategy use becomes an indispensable part of SRL because learners can employ strategies to control information processing involved with learning. In an early study (O'Malley \& Chamot, 1990), learner strategies in second language acquisition emerged from the need to identify the characteristics and behaviors of effective learners. In relation to this, successful language learners could associate new information with existing information in long-term memory and build increasingly intricate and differentiated mental structures. One aspect that distinguishes expert learners from novice learners is more effective use of learning strategies. As documented by Oxford (1990), efficient learners are more likely to use metacognitive strategies, including planning, organizing, and evaluating, that may help them take executive control over their learning. Expert learners are also more willing to use cognitive strategies, including analyzing, reasoning, and transferring information, and summarizing, to achieve better learning outcomes. Exploring strategies that contribute to learning and ways in which strategies interact with social and psychological variables in L2 contexts appears necessary.

In recent years, some researchers revealed the nature of self-regulated writing strategies and the potential of L2 writing strategies for enhancing writing. For example, Teng and Zhang (2016) developed a self-regulated writing strategies questionnaire to understand Chinese EFL students' use of writing strategies. The questionnaire included multiple dimensions of selfregulation, covering cognition, metacognition, social behavior, and motivational regulation. The four dimensions included nine strategies, which were correlated with each other. Specifically, strategies such as text processing, planning, monitoring, evaluating, feedback handing, emotional control, and motivation were significant predictors for EFL students' writing proficiency. In a recent study, Teng and Huang (2019) showed that in addition to metacognitive writing strategies for self-regulating the writing process, the other two facets of metacognition, namely metacognitive knowledge and experiences, can also predict the students' writing performance. Moreover, metacognitive knowledge and regulation collectively accounted for $62 \%$ of the variance in writing performance scores (Teng, 2019a).

The above studies highlighted the strong association between metacognition and writing performance. Writing strategies based on metacognition theories can be applied in EFL writing settings. Although such insights can shed light on academic writing strategies and performance, the above studies failed to explore metacognitive writing strategies in EFL academic writing contexts, let alone an exploration of how the interplay of the various dimensions of metacognition can influence academic writing performance in EFL contexts. Academic writing is not just related to the use of the English language structures, as required in writing, but also involves an ability to define the intellectual boundaries of their disciplines and specific areas of expertise. Bearing in mind the lack of research on academic writing, this empirical study aims to explore the different dimensions of metacognitive academic writing strategies and document how the strategies predict EFL academic writing performance. This study intends to add knowledge to the adoption of self-regulation and metacognition theories in EFL academic writing contexts.

\section{The present study}

Despite conceptual and methodological differences in the above-reviewed studies, metacognition functions as a determining element in writing performance. The present study aims to validate a questionnaire on metacognitive academic writing strategies and to explore the predictive effects of various strategies in EFL academic writing. The focus of 
the present study aims to explore the relationship between each subcomponent of metacognition and EFL academic writing. We propose two structural models to understand the dimensions of metacognitive strategies in EFL academic writing. The first model is an eight-factor correlated model of metacognitive strategies in EFL academic writing. This model splits the 43 items into eight components framed with the metacognition theory. The second model is a one-factor second-order model that explores metacognitive strategies in EFL academic writing. The second model is a competing hierarchy model. In this model, metacognition functions as a single higher-order common factor. We postulate that this common factor could account for the correlations of the eight lower-order strategies. The present study aims to explore the following questions:

1. What structural model best represents the dimensions of metacognitive academic writing strategies?

2. To what extent do metacognitive academic writing strategies predict EFL proficiency in academic writing?

\section{Method}

\section{Participants}

The participants consisted of 664 junior students from a university in the southwestern region of mainland China. The reason for choosing third-year students was because they attended the English for Academic Purpose (EAP) course. Although the learners had more than ten years of experience in learning English, they did not have much experience in academic writing. A total of 752 learners responded to the questionnaire, but the data from 664 students were valid after an examination for missing values, normality, and homogeneity. The participants were informed that when attending this study, they would be asked to complete a survey and perform some writing exercises. They attended the study voluntarily. The consent form stated that they would receive a coupon for attending this study. Participants provided basic information, e.g., age, gender, and years of English learning experience for the consent form. Mandarin Chinese was their first language. The mean age of the participants was 22.13. Of the 664 students, 363 were men and 301 were women.

\section{Questionnaire development}

The Metacognitive Academic Writing Strategies Questionnaire (MAWSQ) was developed for the present study through five processes: item generating, consulting references, initial piloting, psychometric evaluation, and exploratory factor analysis (EFA). At the first stage of item generation, a multi-method technique was adopted (see Appendix A). This technique was focused on helping learners reflect on their writing practice and strategies through some writing exercises. Different academic writing exercises were listed at the beginning of item generation. The learners were then asked questions related to metacognition. According to Dörnyei (2014), involving learners in the process of generating items can ensure the suitable quality of constructs for the questionnaire. To this end, 20 students who were diverse in terms of gender, year level, and disciplinary major were involved. They were invited to describe writing practice and strategies they had possibly used after doing some writing exercises. Based on content analysis of the transcription of 
learners' responses, we generated 60 items related to metacognitive academic writing strategies. The second stage involved consulting relevant literature on SRL or metacognitive language learning strategies (Oxford, 2013; Schraw \& Dennison, 1994; Wolters \& Benzon, 2013). We compared the items we generated with those in established references and selected items that fit with the metacognition and self-regulation theories. Such a procedure imparted construct validity to a questionnaire and the items were judged as appropriate based on relevant theories. The third stage involved initial piloting. We returned the questionnaire to the 20 students to check the items. For example, they checked whether items were ambiguous or not relevant. We eliminated two double-barreled items based on learners' feedback. The fourth stage involved psychometric evaluation. Two experts in the field of language-learning strategies were invited to examine the items. They scrutinized the theoretical rationale, examined the items, and rated the degree to which the items matched the constructs defined in the present study. Based on their feedback, we eliminated five items. The final stage was an EFA analysis, which was based on another sample of 391 students of similar background. Based on EFA, we deleted 10 items that were found to have a factor-loading value of less than 0.30 . The present study finally included a 43 -item scale that met the minimum requirement of cases-to-variables ratio (5:1) analysis (Field, 2009). The final sample of 664 learners also meets the assumptions of linearity, singularity, and homogeneity. Appendix B presents the 43 items of MAWSQ.

The present study adopted a seven-point Likert scale, which ranged from one (Strongly disagree) to seven (Strongly agree). Such a scale could help understand the trait features of the strategies. The mean scores of each sub-component of MAWSQ were used. As learners reported very few metacognitive experiences, the MAWSQ mainly includes two main components: metacognitive knowledge and metacognitive regulation. In terms of metacognitive knowledge, three categories, i.e., declarative knowledge, procedural knowledge, and conditional knowledge, were established. With regard to metacognitive regulation, five categories, i.e., planning, monitoring, evaluating, debugging, and information management, were outlined. Cronbach's alpha was reported to check the internal consistency of responses to items. In terms of declarative knowledge, procedural knowledge, and conditional knowledge, the Cronbach's alphas were 0.792, 0.795, and 0.738, respectively. In terms of planning, monitoring, evaluating, debugging, and information management, the Cronbach's alphas were $0.809,0.826,0.871,0.812$, and 0.809 , respectively. The questionnaire was developed in a bilingual version. The participants completed the Chinese version.

\section{Academic writing test}

This is a single measure of academic writing performance. This test evaluated learners' ability to understand the topic, provide details, outline problems, and provide arguments for a specific academic discipline based on their own knowledge or experience. The main focus of the test was to evaluate the learners' academic writing performance in terms of linguistic competence, critical thinking, and articulation of ideas. In this academic writing test, learners were required to write an essay on a topic related to medicine and health. The topic was chosen in responding to the institutional advocate of enhancing students' awareness of self-care needs due to the COVID-19 pandemic. Learners were presented with six pictures. The learners described what they perceived about the pictures, connected the pictures, and produced a short essay. Each picture was accompanied by some key words. For example, the first picture was about "bacteria and the flu." The learners were provided with a list of words for writing (e.g., bacteria, pills, vitamins, anatomy, donate, chemist, mask, 
beaker, and petri dish). The list of words also included the Chinese meanings for better comprehension by the learners.

The marking scheme was based on four components of writing rubrics adopted in the university, i.e., task achievement, coherence and cohesion, lexical resource, and grammatical range and accuracy. The Cronbach's alpha for the four components of this test ranged from 0.811-0.875, indicating a sound reliability. In order to ensure the face validity of the test (i.e., the accuracy of content), the study involved three researchers with expertise in L2 writing. The total possible score for the test was 24 points, with 6 marks for each component. Three experienced EFL teachers were paid to rate the writings for one class. There were 45 raters involved for the 15 classes where the participants were from. The participants' identity was not revealed to the raters. Prior to scoring, raters had a discussion on marking and sample writings. In each class, the first two raters marked the writings, and when disagreements on marking arose, a third rater would be called upon to have a discussion. The differences were solved based on the majority's opinion. Cohen's kappa coefficient $(\kappa)$ was employed to measure interrater reliability for the 15 classes. The values ranged from $0.71-0.79$, indicating sound interrater reliability.

\section{Procedures}

The questionnaire was administered and completed online. Participants scanned a QR code and completed the questionnaire at the end of the EAP course. The reason for administering the questionnaire at the end of the writing course was to elicit learners' reflection on the use of strategies. Although a strict time limit to complete the questionnaire was not enforced, the learners spent an average of 15 min completing the Chinese version of the MAWSQ. On the following day, learners completed the academic writing test in class. The time allowed for this test was one hour, following the exam practice for writing at this university. The writing test was completed using a paper-and-pencil format. The teacher in each class helped proctor the process. They acted as the test administrators, ensuring that all testing sessions were conducted in the same manner and that participants received the same explanations.

\section{Data analysis}

After testing the plausibility through EFA, the data were analyzed through a series of confirmatory factor analyses (CFA). Data were analyzed through SPSS AMOS program, version 24. CFA is for testing a theoretical model through confirming factors, correlations, covariance patterns, and residual or error values within a data matrix (Byrne, 2016). The maximum likelihood (ML) estimation method was adopted to evaluate the hypothesized models. The models were also evaluated by statistical means to determine the adequacy of its goodness-of-fit (GFI) to the sample data, e.g., it can measure the hypothesized model and the observed covariance. Based on Byrne's (2016) research, the CFA data were also based on following omnibus fit statistics, including a chi-square statistic, the degrees of freedom (df), $p$ value, the ratio of chi-square $\chi^{2}$ divided by the $\mathrm{df}$, the root mean square error of approximation (RMSEA), the standardized root mean square residual (SRMR), the comparative fit index (CFI), and the Tucker-Lewis Index (TLI). Model fit should commonly meet most of the following criteria: the value of GFI should be over 0.90 , the value of RMSEA should be less than 0.1, the value of SRMR should be less than 0.08, and the values for CFI and TLI should be equal to or larger than 0.90 (see Kline, 2011 for details). 
One issue to bear in mind is that we may not achieve satisfactory levels for all indices in a model. In an attempt to compare the hypothesized nested models, we used chi-square statistics to select the appropriate structural model. For example, based on Kline's (2011) research, we examined the differences in chi-square as a ratio of the difference in df. The significant $p$-value indicated that the reference model may be a more appropriate model.

The final procedure was to evaluate the predictive effects of various dimensions of metacognitive academic writing strategies on academic writing performance. We adopted linear regression analysis to understand the extent to which different strategies predicted EFL learners' academic writing performance.

\section{Results}

\section{Descriptive statistics and normality check}

The mean scores of the eight factors ranged from 4.24 to 4.84 with standard deviations ranged from 0.96 to 1.07 . The values for skewness ranged from -0.013 to 0.172 . Finally, the values for kurtosis ranged from 0.166 to 0.627 . According to Kline (1998), the data fit with the requirements of normality assumption. Table 1 presents the means, standard deviations, and normality check for the eight strategies.

\section{CFA results}

Figure 2 shows the standardized results for the three-factor correlated model. The CFA results revealed that the standardized estimate loadings from observed variables to the unobserved variables were all higher than 0.50 , which is a benchmark value that indicates an acceptable effect size (Raykov \& Marcoulides, 2008). The results confirmed the different variables of metacognition were distinct but correlated.

The next step was to check whether the model fit the data well. Results are in Table 2.

Results in Table 2 showed an acceptable model fit $\left(\chi^{2}{ }_{664}=2374.052 ; \mathrm{df}=832\right.$; $p<0.001 ; \quad \chi^{2} / \mathrm{df}=2.853 ; \quad \mathrm{GFI}=0.912 ; \quad \mathrm{RMSEA}=0.054, \quad \mathrm{SRMR}=0.053 ; \quad \mathrm{CFI}=0.917$; $\mathrm{TLI}=0.918$ ). The results provided evidence for validity of the internal structure of the

Table 1 Means, standard deviations, and normality check for the eight strategies

\begin{tabular}{llllll}
\hline Dimensions & $\begin{array}{l}\text { Metacognitive writ- } \\
\text { ing strategies }\end{array}$ & M & SD & Skewness & Kurtosis \\
\hline Metacognitive knowledge & DK (5 items) & 4.84 & 1.02 & -.013 & .527 \\
& PK (4 items) & 4.65 & 1.05 & .014 & .590 \\
& CK (4 items) & 4.46 & .96 & .172 & .627 \\
Metacognitive regulation & P (7 items) & 4.48 & 1.01 & .062 & .514 \\
& M (6 items) & 4.52 & .96 & -.013 & .494 \\
& E (7 items) & 4.65 & 1.02 & .036 & .480 \\
& IMS (5 items) & 4.24 & 1.06 & .142 & .166 \\
& DS (5 items) & 4.29 & 1.07 & .089 & .245 \\
\hline
\end{tabular}

$D K$ Declarative knowledge, $P K$ Procedural knowledge, $C K$ Conditional knowledge, $P$ Planning, $M$ Monitoring, $E$ valuating, IMS Information management strategies, $D S$ Debugging strategies 


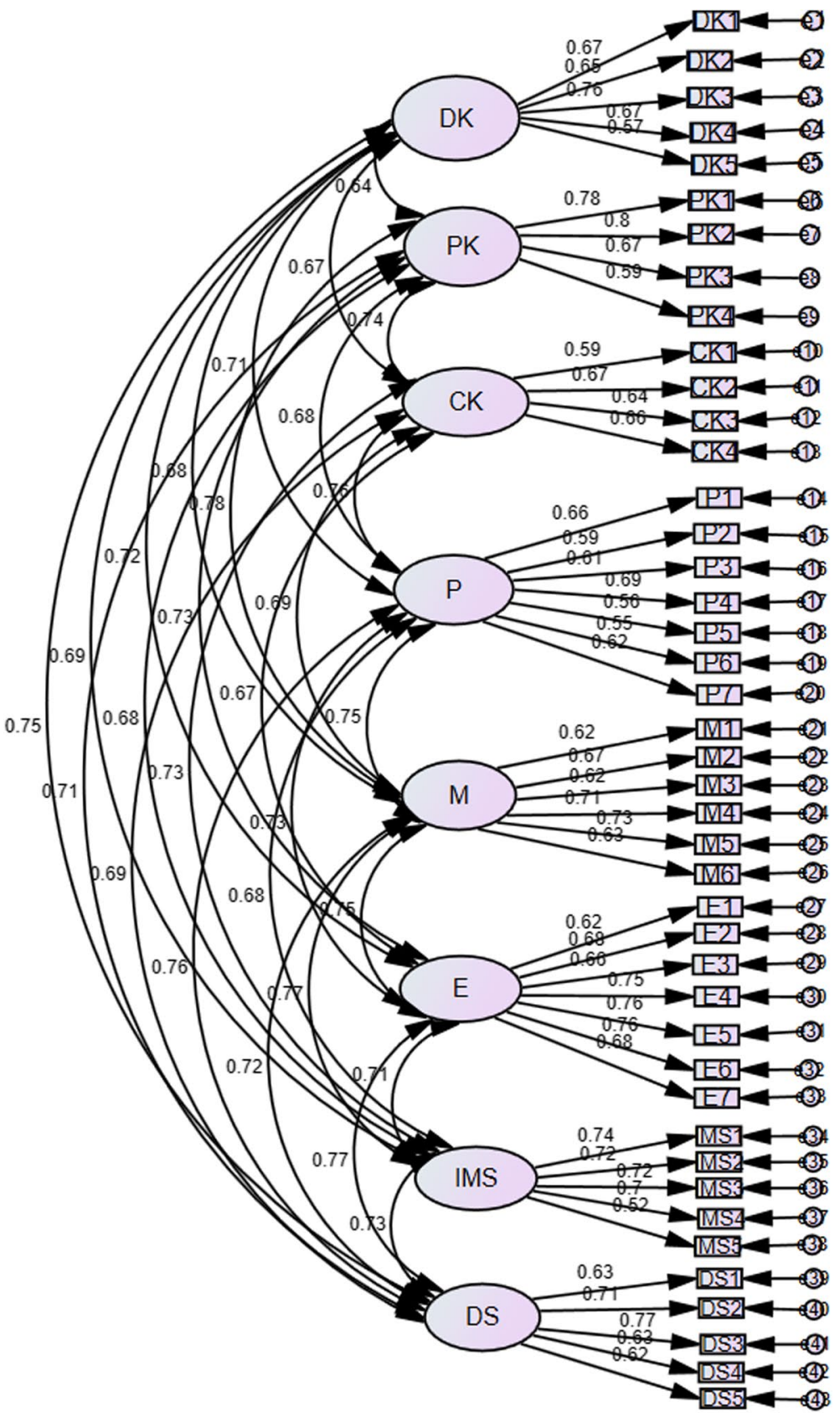

Fig. 2 Eight-factor correlated model of metacognitive strategies for EFL academic writing with standardized regression weight $(N=664)$. Note: $\mathrm{DK}=$ Declarative knowledge; $\mathrm{PK}=$ Procedural knowledge; $\mathrm{CK}=$ Conditional knowledge; $\mathrm{P}=$ Planning; $\mathrm{M}=$ Monitoring; $\mathrm{E}=$ Evaluating; $\mathrm{IMS}=$ Information management strategies; $\mathrm{DS}=$ Debugging strategies 
construct measured. The next step was to present the results of the one-factor second-order model (Fig. 3).

In Fig. 3, the coefficients of the eight strategies ranged between 0.71 and 0.79 on the construct of metacognition, which indicates internal structure of the questionnaire (Kline, 2011). Again, the standardized estimate loadings from observed variables to the unobserved variables were all higher than 0.50 , which represents an acceptable effect size (Raykov \& Marcoulides, 2008). The results confirmed metacognition functioned as a single common factor that included the eight distinct but correlated factors. Results from the model fit indices are also in Table 2.

Results in Table 2 also showed an acceptable model fit $\left(\chi^{2}{ }_{664}=2506.382 ; \mathrm{df}=852\right.$; $p<0.001 ; \quad \chi^{2} / \mathrm{df}=2.942 ; \quad \mathrm{GFI}=0.919 ; \quad \mathrm{RMSEA}=0.055 ; \quad \mathrm{SRMR}=0.057 ; \quad \mathrm{CFI}=0.909$; TFI $=0.908$ ). Again, the overall results showed that the model fit the data well (Kline, 2011). The next step was to compare the two models.

Model comparisons indicated significant improvement from Model 1 to Model 2. The chi-square values in the two models suggested significant differences $\left(\chi_{\mathrm{M} 2}^{2}-\chi_{\mathrm{M} 1}^{2}=132.33\right.$; $\left.\mathrm{df}_{\mathrm{M} 2}-\mathrm{df}_{\mathrm{M} 1}=20 ; p<0.001\right)$, indicating the indices of Model 2 improved significantly over Model 1. Hence, the second model demonstrated that metacognition functions as a hierarchical construct which explains the eight metacognitive strategies. This is an evidence for highlighting metacognition in the EFL academic writing classroom.

\section{Predictive effects of metacognitive academic writing strategies on academic writing}

Results for the correlation between different strategies are in Table 3.

The Pearson correlation coefficients in Table 3 suggest that the DK of the metacognitive component was strongly correlated with PK $(r=0.661), \mathrm{CK}(r=0.597), \mathrm{P}(r=0.606)$, $\mathrm{M}(r=0.618), \mathrm{E}(r=0.676), \mathrm{IMS}(r=0.511)$, and DS $(r=0.529)$. The correlations were all higher than 0.50 , which means that at least $25 \%$ of the variance of one component was explained by the other. Table 5 shows the correlation between academic writing performance and each of the strategies.

Results in Table 4 revealed that each of the eight strategies were significantly correlated with academic writing performance $(p<0.001)$. In particular, AWP was strongly correlated with DK $(r=0.720)$, PK $(r=0.778), \mathrm{CK}(r=0.803), \mathrm{P}(r=0.798), \mathrm{M}(r=0.829), \mathrm{E}$ $(r=0.829)$, IMS $(r=0.752)$, and DS $(r=0.750)$. The final step was to present the regression results (Table 5).

Results showed that the eight metacognitive strategies as a whole explained approximately $87 \%$ of the variance in the EFL students' academic writing scores, $F$ (8,

Table 2 Model fit indices from confirmatory factor analysis

\begin{tabular}{lllllllllll}
\hline Model fit indices & $\chi^{2}$ & df & $p$ & $\chi^{2} / \mathrm{df}$ & GFI & RMSEA & SRMR & CFI & TLI & NFI \\
\hline Criteria & - & - & $<0.05$ & $<3$ & $>0.9$ & $<0.10$ & $<0.08$ & $\geq 0.9$ & $\geq 0.9$ & $>0.9$ \\
Model 1 Value & 2374.052 & 832 & 0.000 & 2.853 & 0.912 & 0.054 & 0.053 & 0.917 & 0.918 & 0.878 \\
Criteria & - & - & $<0.05$ & $<3$ & $>0.9$ & $<0.10$ & $<0.08$ & $\geq 0.9$ & $\geq 0.9$ & $>0.9$ \\
Model 2 Value & 2506.382 & 852 & 0.000 & 2.942 & 0.919 & 0.055 & 0.057 & 0.909 & 0.908 & 0.872 \\
\hline
\end{tabular}




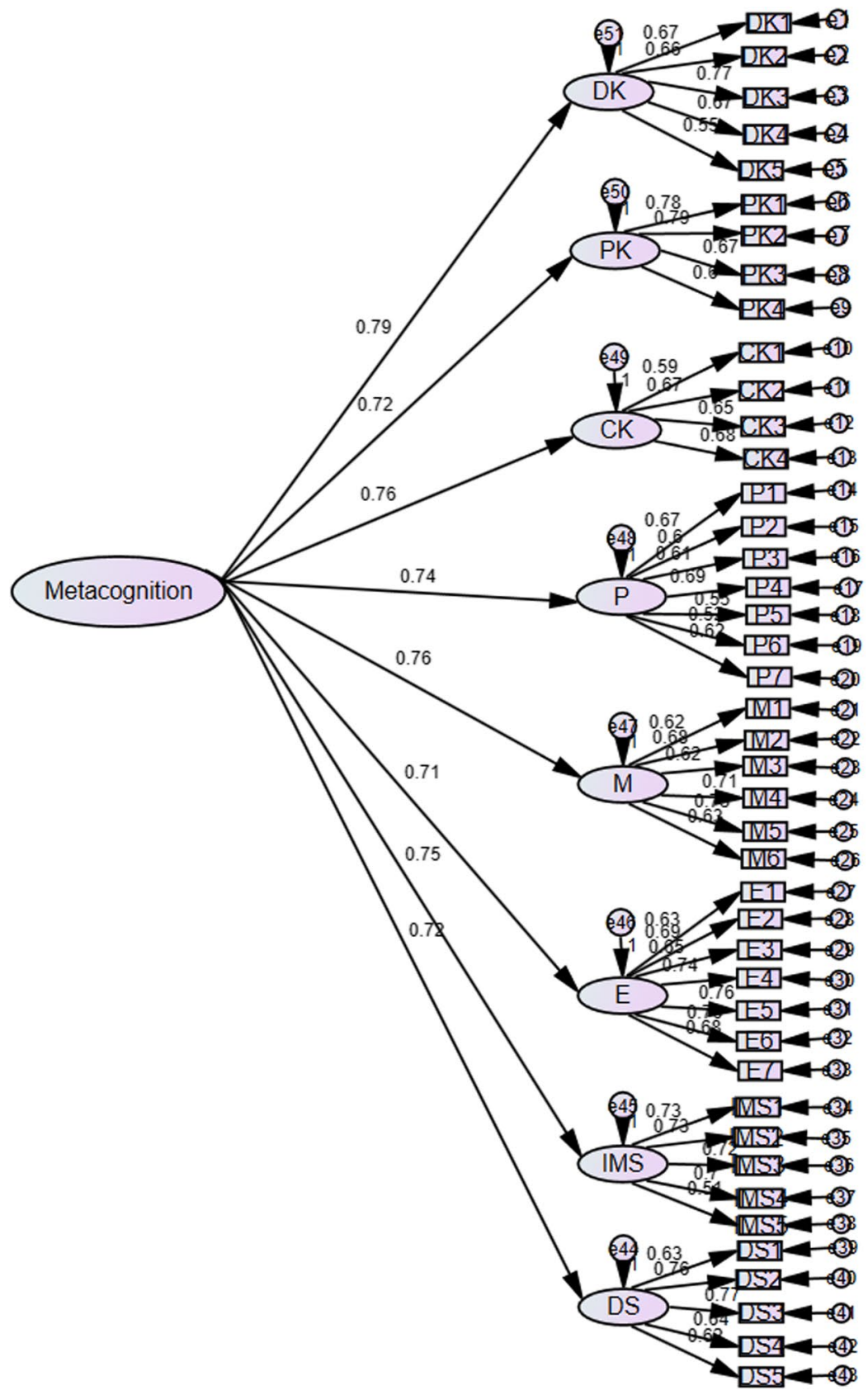

Fig. 3 One-factor second-order model of metacognitive strategies for EFL academic writing $(N=664)$ 
Table 3 Pearson correlation coefficients for the eight metacognitive strategies

\begin{tabular}{lllllllll}
\hline & DK & PK & CK & P & M & E & IMS & DS \\
\hline DK & 1 & & & & & & & \\
PK & 0.661 & 1 & & & & & & \\
CK & 0.597 & 0.671 & 1 & & & & & \\
P & 0.606 & 0.693 & 0.706 & 1 & & & & \\
M & 0.618 & 0.694 & 0.724 & 0.747 & 1 & & & \\
E & 0.676 & 0.727 & 0.749 & 0.709 & 0.774 & 1 & & \\
IMS & 0.511 & 0.579 & 0.663 & 0.689 & 0.71 & 0.632 & 1 & \\
DS & 0.529 & 0.59 & 0.683 & 0.639 & 0.669 & 0.628 & 0.68 & 1 \\
\hline
\end{tabular}

$D K$ Declarative knowledge, $P K$ Procedural knowledge, $C K$ Conditional knowledge, $P$ Planning, $M$ Monitoring, $E$ Evaluating, IMS Information management strategies, $D S$ Debugging strategies

\begin{tabular}{ll}
\hline & AWP \\
\hline DK & $0.720^{* *}$ \\
PK & $0.778^{* *}$ \\
CK & $0.803^{* *}$ \\
P & $0.798^{* *}$ \\
M & $0.829^{* *}$ \\
E & $0.829^{* *}$ \\
IMS & $0.754^{* *}$ \\
DS & $0.750^{* *}$ \\
\hline
\end{tabular}

$A W P$ Academic writing performance, $D K$ Declarative knowledge, $P K$ Procedural knowledge, $C K$ Conditional knowledge, $P$ Planning, $M$ Monitoring, E Evaluating, IMS Information management strategies, $D S$ Debugging strategies

$* p<.05, * * p<.01$

$635)=529.666, p<0.001, R^{2}=0.87$, adjusted $R^{2}=0.868$. The different predicting effects of each strategy on AWP are delineated in Fig. 4.

As shown in Table 5 and Fig. 4, individual sub-categories of metacognition, i.e., DK, PK, CK, P, M, E, IMS, DS, all yielded significant predictions for the EFL learners' academic writing performance $(p<0.001)$.

\section{Discussion}

The first purpose of the present study is to validate a self-reporting instrument, i.e., the Metacognitive Academic Writing Strategies Questionnaire (MAWSQ). The questionnaire was based on the trait features of metacognition. The results provided evidence about the factorial structure of the instrument, entailing metacognitive knowledge and regulation. The findings document the utility of MAWSQ with satisfactory psychometric properties. The eight metacognitive strategies were distinct but correlated with each other. In addition, the eight strategies were reliable in terms of conceptual and empirical grounds. Model 
Table 5 Linear regression results $(N=644)$

\begin{tabular}{|c|c|c|c|c|c|c|c|c|c|}
\hline & \multicolumn{2}{|c|}{$\begin{array}{l}\text { Unstandardized } \\
\text { Coefficients }\end{array}$} & \multirow{2}{*}{$\begin{array}{l}\text { Standardized } \\
\text { Coefficients } \\
\text { Beta }\end{array}$} & \multirow[t]{2}{*}{$\mathrm{t}$} & \multirow[t]{2}{*}{$p$} & \multirow[t]{2}{*}{ VIF } & \multirow[t]{2}{*}{$\mathrm{R}^{2}$} & \multirow[t]{2}{*}{ Adjusted $\mathrm{R}^{2}$} & \multirow[t]{2}{*}{$F$} \\
\hline & B & Std. E & & & & & & & \\
\hline Constant & 1.518 & 0.282 & - & 5.387 & $0.000 * *$ & - & 0.87 & 0.868 & $529.666 * * *$ \\
\hline DK & 0.091 & 0.015 & 0.132 & 6.287 & $0.000 * *$ & 2.136 & & & \\
\hline PK & 0.102 & 0.019 & 0.13 & 5.479 & $0.000 * *$ & 2.747 & & & \\
\hline CK & 0.118 & 0.023 & 0.131 & 5.195 & $0.000 * *$ & 3.105 & & & \\
\hline $\mathrm{P}$ & 0.066 & 0.014 & 0.12 & 4.807 & $0.000 * *$ & 3.06 & & & \\
\hline M & 0.095 & 0.017 & 0.153 & 5.597 & $0.000 * *$ & 3.648 & & & \\
\hline $\mathrm{E}$ & 0.087 & 0.014 & 0.175 & 6.408 & $0.000 * *$ & 3.645 & & & \\
\hline IMS & 0.086 & 0.015 & 0.13 & 5.64 & $0.000^{* * *}$ & 2.592 & & & \\
\hline DS & 0.089 & 0.014 & 0.136 & 6.123 & $0.000 * *$ & 2.4 & & & \\
\hline
\end{tabular}

Dependent variable: AWP

$W P$ Academic writing performance, $D K$ Declarative knowledge, $P K$ Procedural knowledge, $C K$ Conditional knowledge, $P$ Planning, $M$ Monitoring, $E$ Evaluating, $I M S$ Information management strategies, $D S$ Debugging strategies'

${ }^{*} p<.05, * * p<.01, * * * p<.001$

comparisons were based on two competing models: the one-factor second-order model (Model 2) and the eight-factor correlated model (Model 1). Model 2 showed a better model fit than Model 1. The empirical findings support that metacognition functions as a theoretical construct that can account for the significant correlations of eight lower-order metacognitive strategies in academic writing. Consistent with Schraw and Moshman's (1995) study, the construct of metacognition accounts for a "systematic structure of knowledge" that can be used to explain and predict a broad range of learning strategies (p.356). The present study also sheds light on the metacognition theory that deploys a range of strategies related to declarative knowledge, procedural knowledge, conditional knowledge, planning, monitoring, evaluating, information management strategies, and debugging strategies (Schraw $\&$ Dennison, 1994). These strategies are distinct but interact with one another in the metacognitive process. As Paris and Winograd (1990) explained, metacognition is a cyclical process of engaging "self-appraisal and self-management of cognition" (p.17), through which cognitive and personal reflection on knowledge states and abilities, and mental processes that orchestrate different dimensions of problem-solving function together and provide an overall view of learners' thought processes. The sums of the eight strategies collectively indicate the learners' overall metacognition levels. The various strategies included in the metacognition construct help in the conceptualization of learners as individuals who need to be actively engaged in the orchestration of knowledge construction for academic writing.

In the present study, the eight strategies were interpreted with reference to the two core paradigms of metacognition, i.e., metacognitive knowledge and regulation, as conceptualized in early studies (Flavell, 1979; Schraw, 2001; Wenden, 1998). The metacognitive knowledge dimension comprises declarative knowledge, procedural knowledge, and conditional knowledge, reflecting learners' beliefs and knowledge about tasks, strategies, and learners themselves that affects the course and outcome of cognitive enterprise (Flavell, 1979). The metacognitive regulation dimension comprises planning, monitoring, and 


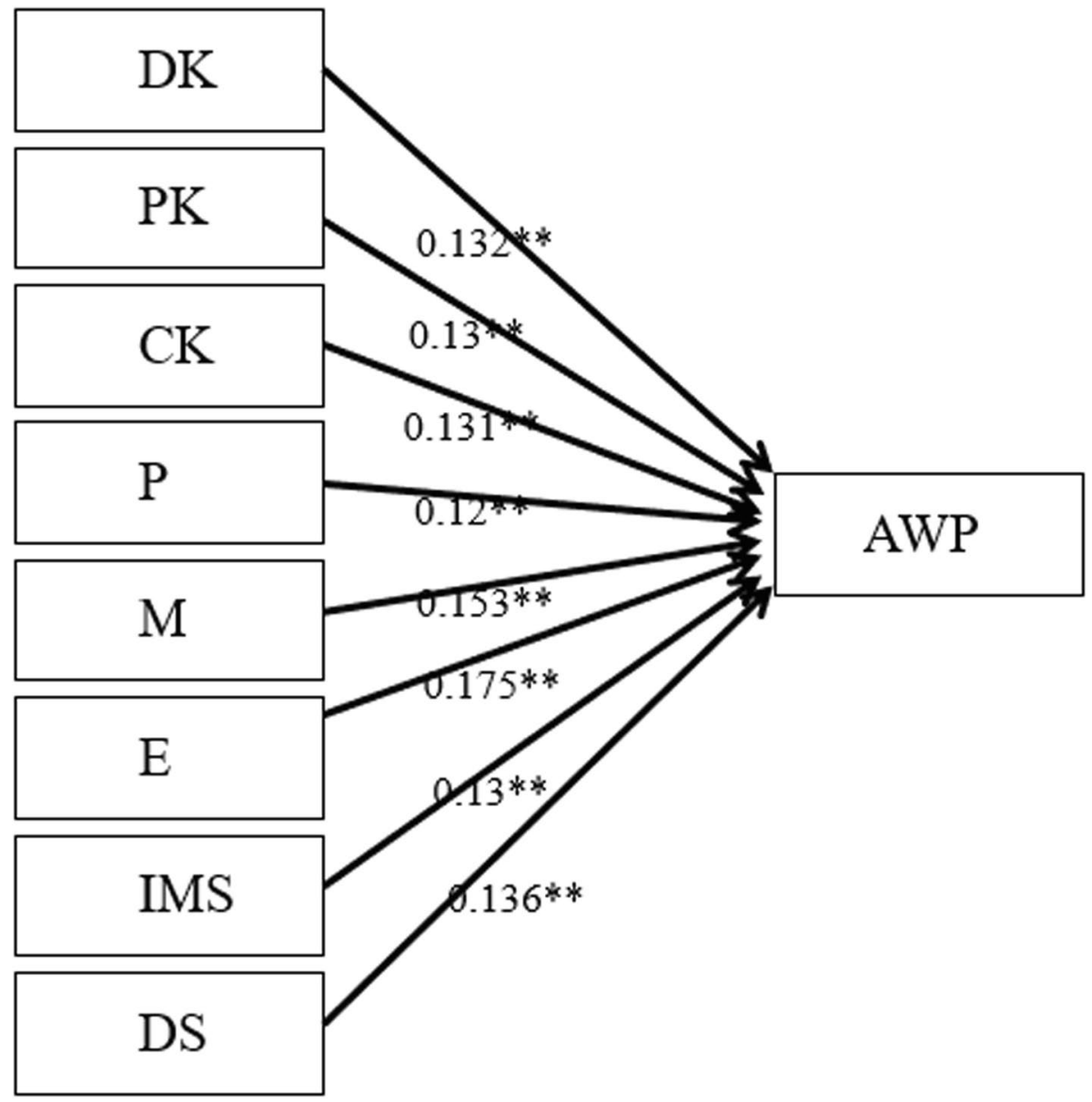

Fig. 4 The predictive effect of metacognitive strategies on academic writing performance

evaluating, reflecting the essential role of regulation in the SRL process (Winne \& Hadwin, 2010). The metacognitive regulation dimension also includes information management strategies and debugging strategies, representing learners' metacognitive control of their learning behaviors in adjusting how the material is used, the task is performed with the material, and how well the material meets the goals (Nilson, 2013). The metacognition dimensions included in the questionnaire conceptualized how learners "[understood] what skills, strategies, and resources [were] required to complete a task as well as how and when to use those skills and strategies" (Schunk \& Zimmerman, 2006, p.360). The findings showed a positive and significant relationship among the various strategies of metacognitive knowledge and regulation, resonating with previous studies (Teng, 2016; Pugalee, 2001). The strong connection between metacognitive knowledge and regulation supports the assertion that EFL students need to deploy a rich repertoire of cognitive, metacognitive, and regulatory knowledge, skills, and strategies in taking control of the learning process (Teng \& Zhang, 2016). As argued by Wolters (1999), strategies in metacognitive knowledge and regulation can "increase students' level of cognitive engagement, overall level 
of effort, and subsequent achievement within an academic setting" (p. 285). The positive correlations between metacognitive knowledge and regulation also lend support to the argument that metacognition provides a "framework for understanding one's as well as the others' cognition and thus guides the interpretation of situational data so that proper control decisions are made" (Efklides, 2006, p.4). The present study provides a strong argument for viewing metacognition as a prominent facet for developing self-regulated learners (Efklides, 2008), as well as "social, motivational, and behavioral processes" as a student writer (Zimmerman \& Risemberg, 1997, p.76).

The second purpose of the present study is to evaluate to what extent that the different strategies related to metacognitive knowledge and regulation predict the EFL learners' performance in academic writing. The results revealed that each of the eight parameters of metacognition was significantly correlated with the EFL students' academic writing performance. The argument presented - at least for this given sample and the adopted test, procedural knowledge, declarative knowledge, conditional knowledge, planning, monitoring, evaluating, information management strategies, and debugging strategies-demonstrated a strong and significant correlation to the EFL students' academic writing performance. The eight metacognitive strategies as a whole explained $87 \%$ of variance in the EFL learners' academic writing performance, lending support to the validity of the one factor secondorder model, in which metacognition functions as an integrated construct that is essential to academic writing. The findings lend support to Flower and Hayes's (1980) cognitive writing model that acknowledges the skills in planning, monitoring, and reviewing process writing. Corresponding to the triadic personal, behavioral, and environmental influences on writer self-regulation (Zimmerman \& Risemberg, 1997), academic writing requires the adaptive use of cognitive or affective strategies, motoric performance strategies, and context-related strategies. As argued by Karlen (2017), apart from knowledge about highquality compositions, students who aim to achieve effective academic writing also need to acquire metacognitive knowledge to regulate and monitor the writing process and to use strategies successfully.

In particular, within the metacognitive knowledge dimension, procedural knowledge, declarative knowledge, and conditional knowledge significantly predicted academic writing scores with a large effect size in our study. Corresponding to previous studies (Brown, 1987; Schraw, 2001), students can become strategic learners when they possess declarative, procedural, and conditional knowledge. Such findings support an argument that EFL learners need to discern knowledge about what strategies are available, how to use those strategies, and how to use elaboration in studying materials to master academic writing. The findings also support studies that argued for the essential role of metacognitive knowledge in fostering active engagement in applying their knowledge about the writing process, identifying the type of strategies valuable in the writing development, and enhancing students' writing outcomes (Kim, 2013; Ruan, 2014).

Within the metacognitive regulation dimension, planning, monitoring, evaluating, information management strategies, and debugging strategies significantly predicted academic writing scores with a large effect size in the current study. These findings support the important role of metacognitive regulation in writing (Teng, 2019a). For example, learners who were more self-regulated in writing appeared to be more skilled in writing. Planning comprised items in goal setting, time management, and writing-resources planning. In examining the EFL learners' use of planning strategies, we detected that Chinese EFL students could plan ahead and organize their thoughts to produce effective written essays. This strategy plays a critical role in ensuring EFL academic writing performance. Learners' development in academic writing could be deemed as a complex process as its 
development is subject to student writers' strategic behavior in seeking knowledge and adjusting planning behaviors. Learners who have planned well for academic writing would normally be the ones who possessed strong metacognitive awareness of writing-oriented goals (Zhang \& Qin, 2018). The items for the monitoring strategy focused on textual-level processing, self-regulation from distractions, lexical resources, and writing adjustment. Corroborating previous studies that stressed the role of monitoring in sustaining writing efforts (Xiang, 2004), such findings supported the assertion that students who could use multiple strategies to conduct metacognitive management of their writing processes might achieve better performance in academic writing. The items in the evaluating strategy focused on self-assessment of language use, writing quality, organization, and content. The findings indicated the need to stimulate learners' self-reflection in evaluating writing performance (Teng, 2020 ). As argued by Travers et al. (2015), learners' metacognitive awareness of strategies, such as self-evaluation and self-reflection in strategy use, expedited learning outcomes. Items in the information management strategy focused on organizing, elaborating, summarizing, and selective focusing. The findings suggest the role of accessing, storing, and analyzing information for writing (Kenkel \& Yates, 2009). Items in the debugging strategy involved learners' behaviors to correct comprehension and performance errors. The findings indicated the need to develop debugging skills for writing, and learners' reported use of this cluster of strategies might help boost their willingness to be self-reflective in correcting their academic essays.

\section{Limitations and implications}

Some limitations for the present study were present. First, even though we demonstrated high content validity through theoretical and empirical validation of the selected strategies, the strategies listed in the questionnaire were still limited. For example, we did not include metacognitive experiences - another important dimension of metacognition - in part, due to the time the learners would be willing to spend in data collection. We did not identify enough strategies related to metacognitive experiences from students' interview data, for which we did not include this dimension in the questionnaire. Second, the present study is based on a self-reported questionnaire. The use of surveys may not accurately assess learners' actual metacognitive awareness and behaviors as it is based on self-reported strategy use. Future studies should triangulate the quantitative data through adding qualitative data to gain a more detailed and in-depth portrayal of learners' metacognition. Third, the academic writing genre is different from the traditional writing genre. The writing test should also cover additional types of exercises that can measure different academic writing skills. However, we only employed a single measure of writing performance. Finally, individual differences, including language learning experiences and language proficiency level, could also impact student writers' performance (Teng \& Huang, 2019). Future research could examine how learner variables influence metacognition and learners' academic performance.

Despite the limitations, the present study is an innovative study that explores the intercorrelated relationship between metacognition and EFL academic writing. First, the developed instrument may be a valid diagnostic tool to be used by EFL classroom practitioners to understand learners' metacognition in academic writing. Teachers need such information to foster and support learners' academic writing through assessing learners' strengths and weaknesses in strategy use related to academic writing. For example, teachers could 
optimize learners' regulative capacity in monitoring and evaluating their writing process. Learners should be supported in reflecting on their strategic behavior. Second, the study provides insight for theoretical understanding of metacognition and academic writing. In particular, the present study sheds light on how different strategies related to metacognitive knowledge and regulation predict learner's academic writing performance. Gaining insight into the interplay between these strategy types and academic writing performance could contribute towards a better understanding of why some student writers achieve outstanding academic writing performance while others struggle. Finally, self-regulatory writing competence, i.e., the adaptation of skills and strategies to learners' writing, should be taught for learners to develop metacognitive awareness of what, how, and why certain choices apply for writing (Teng, 2019b ). Learners need to engage in critical thinking for planning, monitoring, and evaluating their own writing processes. Communicating this message to university English learners would be desirable. The present study highlights the benefit of paying attention to metacognitive regulatory skills for academic writing performance.

Supplementary Information The online version contains supplementary material available at https://doi. org/10.1007/s11409-021-09278-4.

Acknowledgements This paper is supported by the Project from the Education Department of Hainan Province, Project number: Hnky2020ZD-9

Authors' contribution Mark Teng: Coordinated the study. Drafted and revised the manuscript.

Chenghai Qin: Data collection, drafted literature review.

Chuang Wang: Participated in the design of the study and performed the statistical analysis and data interpretation.

All authors proofread and approved the final manuscript.

Data availability The data that support the findings of this study are available on request from the corresponding author, Qin Chenghai. The data are not publicly available due to the possible information that could compromise the privacy of research participants.

\section{Declarations}

Conflicts of interest The authors declare that they have no conflict of interest.

Research involving human participants and/or animals Human participants.

\section{References}

Andrade, M. S., \& Evans, N. W. (2012). Principles and practices for response in second language writing: Developing self-regulated learners. Routledge.

Bereiter, C., \& Scardamalia, M. (1987). The psychology of written composition. Erlbaum.

Brown, A. L. (1987). Metacognition, executive control, self-regulation, and other more mysterious mechanisms. In F. E. Weinert \& R. H. Kluwe (Eds.), Metacognition, motivation, and understanding (pp. 65-116). Lawrence Erlbaum Associates.

Bruning, R., \& Horn, C. (2000). Developing motivation to write. Educational Psychologist, 35, $25-37$.

Bui, G., \& Kong, A. (2019). Metacognitive instruction for peer review interaction in L2 writing. Journal of Writing Research, 11(2), 357-392.

Byrne, B. M. (2016). Structural equation modeling with AMOS (3rd ed.). Routledge.

da Silva Marini, J. A., \& Boruchovitch, E. (2014). Self-regulated learning in students of pedagogy. Paidéia, $24,323-330$. 
Dörnyei, Z. (2014). Questionnaires in second language research: Construction, administration, and processing (2nd ed.). Routledge/Taylor \& Francis.

Efklides, A. (2006). Metacognition and affect: What can metacognitive experiences tell us about the learning process? Educational Research Review, 1, 3-14.

Efklides, A. (2008). Metacognition: Defining its facets and levels of functioning in relation to self-regulation and co-regulation. European Psychologist, 13, 277-287.

Field, A. P. (2009). Discovering statistics using SPSS (3rd ed.). SAGE.

Flavell, J. H. (1979). Metacognition and cognitive monitoring: A new era of cognitive developmental inquiry. American Psychologist, 34, 906-911.

Flavell, J. H. (1985). Cognitive development (2nd ed.). Prentice-Hall.

Flower, L. (1989). Taking thought: The role of conscious processing in the making of meaning. In E. P. Maimon, B. F. Nodine, \& F. W. O’Connor (Eds.), Thinking, reasoning, and writing (pp. 185-212). Longman.

Flower, L., \& Hayes, J. R. (1980). The dynamics of composing: Making plans and juggling constraints. In L. Gregg \& E. Steinberg (Eds.), Cognitive processes in writing (pp. 31-50). Erlbaum.

Flower, L., Wallace, D. L., Norris, L., \& Burnett, R. A. (1994). Making thinking visible: Writing, collaborative planning, and classroom inquiry. National Council of Teachers of English.

Graham, S., \& Harris, K. R. (2000). The role of self-regulation and transcription skills in writing and writing development. Educational Psychologist, 35, 3-12.

Hacker, D. J., Keener, M. C., \& Kircher, J. C. (2009). Writing is applied metacognition. In D. J. Hacker, J. Dunlosky, \& A. C. Graesser (Eds.), Handbook of metacognition in education (pp. 154-172). Routledge.

Hall, N. C., \& Goetz, T. (2013). Emotion, motivation, and self-regulation: A handbook for teachers. Emerald Group Publishing.

Harris, K., \& Graham, S. (2009). Self-regulated strategy development in writing: Premises, evolution, and the future. British Journal of Educational Psychology (Monograph Series), 6, 113-135.

Hyland, K. (2003). Genre-based pedagogies: A social response to process. Journal of Second Language Writing, 12, 17-29. https://doi.org/10.1016/S1060-3743(02)00124-8

Karlen, Y. (2017). The development of a new instrument to assess metacognitive strategy knowledge about academic writing and its relation to self-regulated writing and writing performance. Journal of Writing Research, 9, 61-86.

Kline, R. B. (1998). Methodology in the social sciences. Principles and practice of structural equation modeling. New York: Guilford Press.

Kenkel, J., \& Yates, R. (2009). The interlanguage grammar of information management in L1 and L2 developing writing. Written Communication, 26(4), 392-416.

Kline, R. B. (2011). Principles and practice of structural equation modeling (3rd ed.). Guilford.

Kim, S. H. (2013). Metacognitive knowledge in second language writing. Unpublished doctoral thesis. Michigan State University.

Lockl, K., \& Schneider, W. (2006). Precursors of metamemory in young children: The role of theory of mind and metacognitive vocabulary. Metacognition and Learning, 1(1), 15-31.

Ma, J., \& Teng, F. (2021). Metacognitive knowledge development of students with differing levels of writing proficiency in a process-oriented course: An action research study. In B. L. Reynolds \& F. Teng (Eds.), Innovative approaches in teaching writing to Chinese speakers (pp. 92-117). DeGruyter.

Nelson, T. O. (1996). Consciousness and metacognition. American Psychologist, 51(2), 102-116.

Negretti, R. (2012). Metacognition in student academic writing: A longitudinal study of metacognitive awareness and its relation to task perception, self-regulation, and evaluation of performance. Written Communication, 29(2), 142-179.

Nilson, L. (2013). Creating self-regulated learners: Strategies to strengthen students' self-awareness and learning skills. Stylus Publishing.

O’Malley, J. M., \& Chamot, A. U. (1990). Learning strategies in second language acquisition. Cambridge University Press.

Oxford, R. L. (1990). Language learning strategies: What every teacher should know. Heinle \& Heinle.

Oxford, R. L. (2013). Teaching and researching language learning strategies (2nd ed.). Pearson.

Paris, S., Cross, D. R., \& Lipson, M. Y. (1984). Informed strategies for learning: A program to improve children's reading awareness and comprehension. Journal of Educational Psychology, 76, 1239-1252.

Paris, S., \& Winograd, P. (1990). How metacognition can promote academic learning and instruction. In B. F. Jones \& L. Idol (Eds.), Dimensions of thinking and cognitive instruction (pp. 15-51). Erlbaum Associates.

Pugalee, D. K. (2001). Writing, mathematics, and metacognition: Looking for connections through students' work in mathematical problem solving. School Science and Mathematics, 101(5), 236-245. 
Raimes, A. (1987). Language proficiency, writing ability, and composing strategies: A study of ESL college student writers. Language Learning, 37(3), 439-468.

Reynolds, B. L., \& Teng, F. (Eds.). (2021). Innovative approaches in Teaching writing to Chinese speakers. De Gruyter Mouton.

Ruan, Z. (2014). Metacognitive awareness of EFL student writers in a Chinese ELT context. Language Awareness, 23(1-2), 76-91.

Raykov, T., \& Marcoulides, G. A. (2008). An introduction to applied multivariate analysis. New York, NY: Routledge.

Sun, T., \& Wang, C. (2020). College students' writing self-efficacy and writing self-regulated learning strategies in learning English as a foreign language. System, 90, 102221.

Sasaki, M., Mizumoto, A., \& Murakami, A. (2018). Developmental trajectories in L2 writing strategy use: A self-regulation perspective. The Modern Language Journal, 102(2), 292-309.

Schraw, G., \& Dennison, R. S. (1994). Assessing metacognitive awareness. Contemporary Educational Psychology, 19, 460-475.

Schraw, G., \& Moshman, D. (1995). Metacognitive theories. Educational Psychology Review, 7(4), 351-371.

Schraw, G. A. (1998). Promoting general metacognitive awareness. Instructional Science, 26, 113-125.

Schraw, G. A. (2001). Promoting general metacognitive awareness. In H. J. Hartman (Ed.), Metacognition in learning and instruction: Theory, research and practice (pp. 3-16). Springer.

Schunk, D. H., \& Zimmerman, B. J. (2006). Competence and Control Beliefs: Distinguishing the Means and Ends. In P. A. Alexander \& P. H. Winne (Eds.), Handbook of educational psychology (pp. 349-367). Lawrence Erlbaum Associates Publishers.

Schunk, D. H., \& Zimmerman, B. J. (2012). Self-regulation and learning. In I. B. Weiner (Ed.), Handbook of psychology (7th ed., pp. 59-78). John Wiley \& Sons Inc.

Shimamura, A. P. (2000). Toward a cognitive neuroscience of metacognition. Consciousness and Cognition, 9, 313-323.

Teng, F., \& Zhang, L. J. (2021). Development of children's metacognitive knowledge, and reading and writing proficiency in English as a foreign language: Longitudinal data using multilevel models. British Journal of Educational Psychology. https://doi.org/10.1111/bjep.12413

Teng, L. S., \& Zhang, L. J. (2016). A questionnaire-based validation of multidimensional models of selfregulated learning strategies. Modern Language Journal, 100(3), 674-701.

Teng, F. (2019a). The role of metacognitive knowledge and regulation in mediating university EFL learners' writing performance. Innovation in Language Learning and Teaching. https://doi.org/10.1 $080 / 17501229.2019 .1615493$

Teng, F. (2019b). A comparison of text structure and self-regulated strategy instruction for elementary school students' writing. English Teaching: Practice and Critique, 18(3), 281-297.

Teng, F. (2020). Tertiary-level students' English writing performance and metacognitive awareness: A group metacognitive support perspective. Scandinavian Journal of Educational Research, 64(4), $551-568$.

Teng, F., \& Huang, J. (2019). Predictive effects of writing strategies for self-regulated learning on secondary school learners' EFL writing proficiency. TESOL Quarterly, 53, 232-247.

Teng, F. (2016). Immediate and delayed effects of embedded metacognitive instruction on Chinese EFL students' English writing and regulation of cognition. Thinking Skills \& Creativity, 22, 289-302.

Travers, C., Morisano, D., \& Locke, E. (2015). Self-reflection, growth goals, and academic outcomes: A qualitative Study. British Journal of Educational Psychology, 85(2), 224-241.

Veenman, M. V. J., \& Elshout, J. J. (1999). Changes in the relation between cognitive and metacognitive skills during the acquisition of expertise. European Journal of Psychology of Education, XIV, 509-523.

Vygotsky, L. S. (1987). Thinking and speech. In R.W. Rieber \& A.S. Carton (Eds.), The collected works of L.S. Vygotsky, Volume 1: Problems of general psychology (pp. 39-285). New York: Plenum Press.

Wang, W., \& Wen, Q. (2002). L1 use in the L2 composing process: An exploratory study of 16 Chinese EFL writers. Journal of Second Language Writing, 11, 225-246.

Weinstein, C. E., \& Mayer, R. E. (1986). The teaching of learning strategies. In M. C. Wittrock (Ed.), Handbook of research on teaching (3rd ed., pp. 315-327). Macmillan.

Wenden, A. L. (1998). Metacognitive knowledge and language learning. Applied Linguistics, 19, 515-537.

Wenden, A. L., \& Rubin, J. (1987). Learner Strategies in Language Learning. Prentice-Hall.

Winne, P. H., \& Hadwin, A. F. (2010). Self-regulated learning and socio-cognitive theory. In P. Penelope, B. Eva, \& B. McGaw (Eds.), International encyclopedia of education (pp. 503-508). Elsevier. 
Wolters, C. A. (1999). The relation between high school students' motivational regulation and their use of learning strategies, effort, and classroom performance. Learning \& Individual Differences, 11, 281-299.

Wolters, C. A., \& Benzon, M. B. (2013). Assessing and predicting college students' use of strategies for the self-regulation of motivation. Journal of Experimental Education, 81, 199-221.

Woodrow, L. (2011). College English writing affect: Self efficacy and anxiety. System, 39, 510-522.

Xiang, W. (2004). Encouraging self-monitoring in writing by Chinese students. ELT Journal, 58(3), 238-246.

Zeng, D. Q. (2005). The process-oriented approach to ESL/EFL writing instruction and research. CELEA Journal, 28(5), 66-70.

Zhang, L. J., \& Qin, L. (2018). Validating a questionnaire on EFL Writers' metacognitive awareness of writing strategies in multimedia environments. In Å. Haukås, C. Bjørke, \& M. Dypedahl (Eds.), Metacognition in Language Learning and Teaching (pp. 157-178). Routledge.

Zhao, H. (2010). Investigating learners' use and understanding of peer and teacher feedback on writing: A comparative study in a Chinese English writing classroom. Assessing Writing, 15, 3-17.

Ziegler, A., Stoeger, H., \& Grassinger, R. (2011). Actiotope model and self-regulated learning. Psychological Test and Assessment Modeling, 53, 141-160.

Zimmerman, B. J. (1989). A social cognitive view of self-regulated academic learning. Journal of Educational Psychology, 81(3), 329-339.

Zimmerman, B. J. (2002). Becoming a self-regulated learner: An overview. Theory into Practice, 41(2), 64-70.

Zimmerman, B. J. (2011). Motivational sources and outcomes of self-regulated learning and performance. In B. J. Zimmerman \& D. H. Schunk (Eds.), Handbook of self-regulation of learning and performance (pp. 49-64). Lawrence Erlbaum.

Zimmerman, B. J. (2013). From cognitive modeling to self-regulation: A social cognitive career path. Educational Psychologists, 48, 135-147.

Zimmerman, B. J., \& Risemberg, R. (1997). Becoming a self-regulated writer: A social cognitive perspective. Contemporary Educational Psychology, 22, 73-101.

Zimmerman, B. J., \& Schunk, D. H. (2001). Self-regulated learning and academic achievement: Theoretical perspectives (2nd ed.). Erlbaum.

Publisher's note Springer Nature remains neutral with regard to jurisdictional claims in published maps and institutional affiliations. 